\title{
Common Peroneal Nerve Palsy after Liver Transplantation
}

\section{Albert CY Chan*}

Department of Surgery, Queen Mary Hospital, Hong Kong

\section{Introduction}

Common peroneal nerve (CPN) palsy is a well-recognized complication after pelvic surgery and gynecological procedure when a lithotomy position is frequently adopted. This postoperative morbidity is both physically and psychologically disturbing to the patient. However, its occurrence after orthotropic liver transplantation is exceedingly rare and is seldom reported $[1,2]$. We therefore reviewed our experience of CPN palsy after liver transplantation.

\section{Materials and Methods}

From October 1991 to November 2010, 851 liver transplantations and 507 living donor hepatectomies were performed in our centre. Among them, three recipients (two deceased donor liver transplantations, DDLT; and one live donor liver transplantation, LDLT) and two donors developed CPN palsy after the operation. All these nerve injuries were detected by clinical examination within one week after surgery and their clinical scenarios are discussed below.

\section{Patient ergonomics in operating theatre:}

The patient is placed in a supine position with both legs in neutral position. The left arm is kept in abduction to allow insertion of large bore intravenous catheter and arterial line. The right arm is kept by the side of the trunk so as to free up the rail on the side of the operating table for mounting of the Bookwalter retractor $\left(\operatorname{Codman}^{\mathrm{TM}}\right.$, Johnson \& Johnson). A urinary Foley catheter is inserted. The posterior and lateral aspects of both knee joints are cushioned by a pair of sponges in order to absorb any extrinsic pressure onto that area (Figure 1). Below knee anti-thrombotic elastic stockings (TED ${ }^{\mathrm{TM}}$, Tyco healthcare) are worn. The thigh regions are then covered by a sheet and above them places a belt across the knees so as to secure the position of the legs onto the operating table (Figure 2). Pneumatic cuffs around the calf regions are inflated to $30 \mathrm{mmHg}$ as anti-thrombotic measure. The superior border of the cuff is positioned not too high to avoid impingement on the fibular head. The skin is then cleansed by anti-septic solution and draped by disposable adhesives. Technical details of the operations were covered in previous publications $[3,4]$.

Case 1: A 49-year old patient underwent (DDLT) for acute deterioration of chronic hepatitis B (HBV) infection [5]. He had no other previous illness. His body weight was $78 \mathrm{~kg}$ and height was 167 $\mathrm{cm}$. The body mass index (BMI) was 28.0. He was an ex-smoker. The American Society of Anesthesiology score (ASA) was 3 and the model for end stage liver disease (MELD) score was 32 . The total operating time was 642 minutes and blood loss was $2700 \mathrm{ml}$. He was found to have left leg numbness and weakness on day 4 after transplantation. His left leg returned to normal after 5-months of physiotherapy.

Case 2-3: The two patients aged 55 and 47 -year old respectively. The indications for transplantations in both patients were HBV-related liver cirrhosis. DDLT and LDLT were performed respectively. Both patients were not diabetic. Their body weights were $71 \mathrm{~kg}$ and $69 \mathrm{~kg}$, and their body heights were $167 \mathrm{~cm}$ and $161 \mathrm{~cm}$. The BMIs were 25.5 and 26.6 respectively. Both patients had an ASA score of 3. The MELD score was 13 and 26. The durations of operations were 640 and 865 minutes. The perioperative blood loss was $12000 \mathrm{ml}$ and $2017 \mathrm{ml}$ respectively. Both patients developed intraoperative cardiac arrest for 30 and 60 seconds that were successfully reversed by cardiac massage. Bilateral foot drops were observed in both patients but fortunately normal gait was restored after a prolonged course of active physiotherapy.

Case 4-5: The two live liver donors were 45 and 22-year old respectively. Both donors had no previous illness. The latter patient was a chronic smoker. The body weights were $46.5 \mathrm{~kg}$ and $66 \mathrm{~kg}$, and the body heights were $145.5 \mathrm{~cm}$ and $174.2 \mathrm{~cm}$ respectively. The BMIs were 22.0 and 21.7 respectively. The total operating times were 780 and 521 minutes. Blood loss was $500 \mathrm{ml}$ and $450 \mathrm{ml}$. Both patients were detected to have left foot drop after donor right hepatectomy that was eventually resolved after a course of physiotherapy.

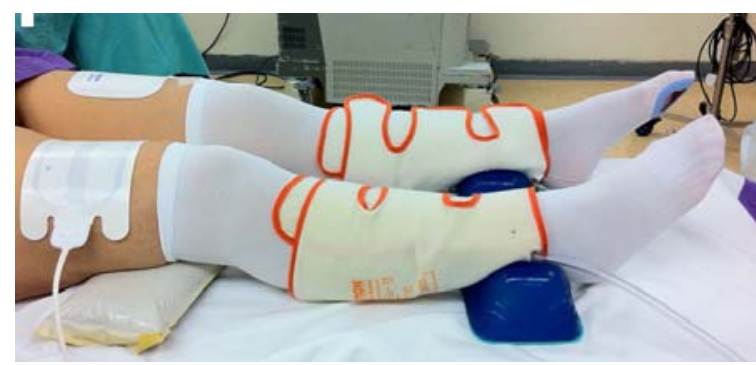

Figure 1: Above-knee TED stockings and position of pneumatic cuff.

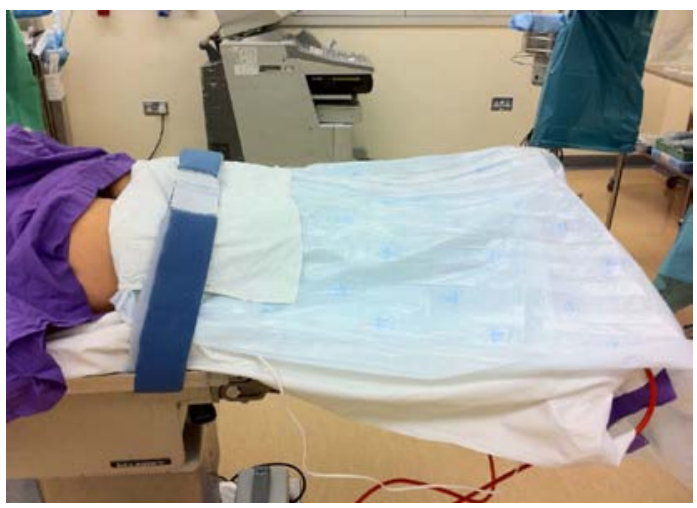

Figure 2: Both legs are strapped on the operating table by a belt.

${ }^{*}$ Corresponding author: Dr. Albert CY Chan, Department of Surgery, Queen Mary Hospital, Hong Kong, E-mail: acchan@hku.hk

Received October 24, 2011; Accepted March 14, 2012; Published March 16 2012

Citation: Chan AC (2011) Common Peroneal Nerve Palsy after Live Transplantation. J Liver 1:103. doi:10.4172/2167-0889.1000103

Copyright: (c) 2011 Chan AC. This is an open-access article distributed under the terms of the Creative Commons Attribution License, which permits unrestricted use, distribution, and reproduction in any medium, provided the original author and source are credited. 


\section{Discussion}

The overall incidence of $\mathrm{CPN}$ in our series is $0.35 \%$ among transplant recipients and $0.39 \%$ among liver donors. It is a well-known complication for operation performed in a lithotomy position [6] but is uncommon in supine position. Risk factors for postoperative CPN palsy include prolonged operating time ( $\geq 4$ hours) [7], a light body weight (BMI20) [1,7], a medical history of diabetes mellitus [8] or smoking habits [7]. However, it is difficult to envisage that prolonged operating time as a significant risk factor in patients receiving liver transplantation. Moreover, all our patients had a BMI more than 20 and none of them were diabetic. Two of our patients were active smokers but its association with CPN palsy is unclear. Therefore, other plausible clinical factors could attribute to the pathogenesis of this nerve injury. In fact, both of our patients who had bilateral foot drop had a brief episode of intraoperative cardiac arrest. We postulated that both surgeons and the assistants may have unintentionally and excessively inclined their arms or upper trunk onto the patient's legs during cardiopulmonary resuscitation resulting in nerve compression or traction. On the other hand, the other three nerve injuries were all localized to the left leg. From our experience, we postulated that patient positioning during mobilization of the right liver and inferior vena cava (IVC) may contribute to the occurrence of this complication. In practice, our patients are kept in a supine position with both knees paddled by sponges and secured on the operating table by a belt. In such position, it is unlikely that extrinsic compression on the fibular neck where the CPN passes by would occur. However, the situation might be different when the orientation of the operating table is altered. We often tilt the operating table to the left during mobilization of the right liver from the triangular ligament and the diaphragm until the IVC is reached [3]. Tilting the table improves the exposure of the precaval and retrocaval area that would facilitate mobilization of the IVC from the retro peritoneum in recipient total hepatectomy in LDLT and dissection of the retrohepatic veins in donor right hepatectomy. This maneuver also facilitates mobilization of the IVC from retro peritoneum in DDLT when a free retrohepatic portion of IVC is needed for total hepatectomy and an end-to-end caval anastomosis with the liver graft. However, excessive and prolonged tilting of the operating table to the left could turn the lax left knee into a valgus position and given that the centre of gravity is already shifted to the left side of the body, the additional weight on the left knee joint would act against the holding belt on the operating table resulting in nerve compression against the fibular neck, and hence the nerve palsy. Another possible mechanism of injury was related to the elasticity of the TED stockings. In patients with profound leg edema up to the knee level, the tourniquet effect caused by the elasticity of TED stocking would lead to nerve compression against odematous soft tissue and bony prominence. When this occurs at the level of the fibular neck due to mis-placement of the upper edge of TED stocking, it could lead to pressure on the CPN and this could be a contributory factor for the development of CPN palsy in the very sick patients with severe hypoalbuminaemia secondary to end-stage liver diseases.

All our patients eventually recovered from this disabling complication after a prolonged course of physiotherapy and use of orthosis. However, this added morbidity is easily avoidable providing that the operating surgeon is fully aware of the clinical implication of excessive movement of the operating table.

In conclusion, CPN palsy is a rare but possible complication after liver transplantation. Surgical factor may attribute to the occurrence of this nerve injury. Vigilance to avoid excessive and prolonged tilting of the operating table may help to prevent this disabling complication. Active physiotherapy holds the key for good recovery.

\section{References}

1. Nonthasoot B, Sirichindakul B, Nivatvongs S, Sangsubhan C (2006) Common peroneal nerve palsy: an unexpected complication of liver surgery. Transplant Proc 38: 1396-1397.

2. Menegaux F, Keeffe EB, Andrews BT, Egawa H, Monge $H$, et al. (1994) Neurological complications of liver transplantation in adult versus pediatric patients. Transplantation 58: 447-450.

3. Fan ST (2007) Living donor liver transplantation

4. Starzl TE, Groth CG, Brettschneider L, Penn I, Fulginiti VA, et al. (1968) Orthotopic homotransplantation of the human liver. Ann Surg 168: 392-415.

5. Chan AC, Fan ST, Lo CM, Liu CL, Chan SC, et al. (2009) Liver transplantation for acute-on-chronic liver failure. Hepatol Int 3: 571-581.

6. Warner MA, Warner DO, Harper CM, Schroeder DR, Maxson PM (2000) Lower extremity neuropathies associated with lithotomy positions. Anesthesiology 93: 938-942.

7. Warner MA, Martin JT, Schroeder DR, Offord KP, Chute CG (1994) Lowerextremity motor neuropathy associated with surgery performed on patients in a lithotomy position. Anesthesiology 81: 6-12.

8. Massey EW, Pleet AB (1980) Compression injury of the sciatic nerve during a prolonged surgical procedure in a diabetic patient. J Am Geriatr Soc 28: 188189. 